\section{Revista de la \\ Universidad del Thulia}

Fundada en 1947 por el Dr. Jesúns Enrique Lossada

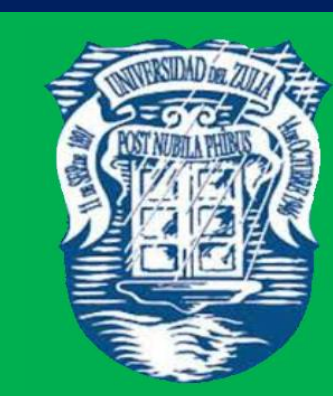

Ciencias del

Algreo

Ingemieria

y Teemología

\section{Aกัต 11 No 29}

Enero - Abril 2021

Tercera Época

Maracaibo-Venezuela 


\title{
Molecular Dynamic Studies and Experimental Methods for Dispersion of Graphene Sheets with Different Strategies
}

\author{
Hashem Ahmadin * \\ Karim Zare * \\ Majid Monajjemi ** \\ Ali Shamel ***
}

\begin{abstract}
Graphene sheets tend to self-associate in microscale aggregates. This occurs in products with less mechanical and electrical action. Recognizing this problem, extensive research has been evidenced in the literature on the development of dispersion technologies, based on both mechanical and chemical approaches. Chemically converted sheets wrapped in surfactants, the ability of surfactants to disperse graphene nanospheres in a medium, was evaluated by different research groups, using both experimental and molecular dynamics (DM) simulation methods; In this article we summarize these methods and techniques. The effect of the influencing factors that count the ions, the $\mathrm{pH}$ value and the surfactants in the separation and agglomeration of the gerata sheets is highlighted. Here, we reviewed the recent advances that have been made in the dispersion of graphene sheets in aqueous and organic media by non-covalent adsorption of surfactants and polymers. Graphene structure, properties, and mainly self-assembly are also studied.

KEY WORDS: anionic surfactants, molecular dynamics studies, exfoliation, graphene.
\end{abstract}

*Depatment of Chemistry, Science and Research Branch, Islamic Azad University, Tehran, Iran, k-zare@srbiau.ac.ir

**Department of Chemical Engineering, Central Tehran Branch, Islamic Azad University, Tehran, Iran.

***Department of Chemistry, Ardabil Branch, Islamic Azad University, Ardabil, Iran.

Recibido: 15/01/2020

Aceptado: 26/02/2020 


\section{Estudios de dinámica molecular y métodos experimentales para la dispersión de láminas de grafeno con diferentes estrategias}

RESUMEN

Las láminas de grafeno tienden a autoasociarse en agregados a microescala. Esto ocurre en productos con menor acción mecánica y eléctrica. Reconociendo este problema, se ha evidenciado una extensa investigación en la literatura sobre el desarrollo de tecnologías de dispersión, basadas en enfoques tanto mecánicos como químicos. Láminas de grafeno convertidas químicamente envueltas en tensioactivos, la capacidad de los tensioactivos para la dispersión de nanoesferas de grafeno en un medio, fue evaluada por diferentes grupos de investigación, mediante métodos de simulación tanto de experimentación como de dinámica molecular (DM); en este artículo resumimos estos métodos y técnicas. Se destaca el efecto de los factores influyentes que cuentan los iones, el valor del pH y los tensioactivos en la separación y aglomeración de las láminas de gerata. Aquí, se revisaron los avances recientes que se han realizado en la dispersión de láminas de grafeno en medios acuosos y orgánicos por adsorción no covalente de tensioactivos y polímeros. También se estudia la estructura de grafeno, propiedades y principalmente el autoensamblaje.

PALABRAS CLAVE: tensioactivos aniónicos, estudios de dinámica molecular, exfoliación, grafeno.

\section{Introduction}

Graphene, a two-dimensional, one-atom-thick hexagonal lattice of carbon atoms has electronic, mechanical, optical, thermal, and chemical properties. graphene has generated huge interest due to its unprecedented physical and chemical properties because of its atom arrangement (Javadian and Khosravian, 2018). A graphene sheet consists of an atomically thin array of sp2-bonded carbon atoms organized in a planar hexagonal arrangement, where each atom is connected evenly to three carbons $\left(120^{\circ}\right)$ in the xy plane, and a weak $\pi$ bond is present in the $z$ axis. The sp2 set forms the hexagonal (honeycomb) lattice typical of a sheet of graphite. The pz orbital is responsible for van der Waals interactions. The free electrons in the pz orbital move within this cloud and are no longer local to a single carbon atom (Vaisman et. Al, 2006; Bjork, 2010). Owing to graphene's unusual physicochemical properties and 
tremendous potential for applications in nanoelectronics, sensors, nanocomposites, batteries, supercapacitors, and hydrogen storage, the development of efficient approaches to producing single-layer. Also the earliest graphene samples were produced using micromechanical cleavage from highly ordered pyrolytic (Du et al., 2008; Morozov et al., 2008).

Graphite has been used by man for thousands of years the details of its layered structure were only revealed by Bernal in 1924 using X-ray crystallography (Bernal, 1924; Boardman et al., 2008). Graphene layers are held together by van der Waals forces in graphite; tend to self-associate into micro-scale aggregates this creates problems both in exfoliating graphene from graphite as well as keeping graphene dispersed in a liquid medium rather than aggregating (Li et al., 2008).

Thermodynamic arguments suggested that graphene could not exist as a freestanding entity. The novel electronic properties of graphene In addition it is the strongest material known to manl0 and has been fabricated into large area transparent conductors. graphene sheets has been intensively explored in recent year Du et al., 2008; Bunch et al., 2007).

Micromechanical cleavage from bulk graphite was initially used by Novoselov and coworkers in 2004 to produce graphene flakes, but the yield of this method is extremely low and the process is hard to control (Novoselov et al., 2004). After that several efforts have been reported by several research groups to separate graphene sheets a number of new methods of graphene production have been developed such as annealing SiC substratesl2 or growth on metal support and methods based on exfoliation or chemical oxidation of graphite or heat treatment of silicon carbide. Oxidation of graphite to graphene oxidel (GO) allows for a high-yielding route to exfoliated carbon nanosheets. The GO sheets disperse readily in water due to the presence of hydrophilic oxygen groups on the basal planes and edges (Lomeda et al., 2008).

Two basic methods of top-down, and the bottom-up approaches there are for fabrication of pure single-layer graphene sheets good method for fabrication of singlelayer graphene sheets should have two main properties: first, the entire preparation process proceeds under mild conditions, and second no hazardous agents are involved. 
Several methods are developed for produce graphene from graphite., graphene may be produced through exfoliation (through sonication or high shear) of graphite powder . in a solution of stabilizer molecules such as micelle-forming surfactants, polymers, and aromatic hydrocarbons and oxidizing of graphite. A good strategy for producing high quality single-layer graphene sheets is using anionic and cationic surfactants. Main challenges for integration of this unique nano-material include: (1) uniform dispersion; (2) preferential alignment in liquid and melt phases; and (3) mass-production of highpurity material at low costs (Vaisman et al., 2006).

\section{Graphen Dispersion methods}

\section{1.l. Liquid Exfoliation of Graphite}

Liquid exfoliated graphene can be used for a range of applications: graphene dispersions as optical limiters, films of graphene flakes as transparent conductors or sensors, and exfoliated graphene as a mechanical reinforcement for polymer-based composites (Coleman, 2012).

Graphite is exfoliated either in organic solvents with the suitable surface energies or in aqueous solution of surfactants (Ciesielski and Samorì, 2014; Bourlinos et al., 2006). Different factors including ions, $\mathrm{pH}$ value and surfactants on graphene sheets separation and agglomeration are very important. Different research groups studied the effect of these parameters.

\subsubsection{Surfactant}

It is still challenging to synchronize prime goals of high quality, good yield, large sheet size, stable long term storage and low cost eco-friendly processing. We present a simple and inexpensive green route for large scale production of exfoliated graphene. self-assembly of surfactant molecules on the graphene surface is of great importance for better preparation and application of graphene: In the dispersion and preparation of graphene, surfactant adsorption on the graphene surfaces can assist the exfoliation and dispersion of graphene nanoparticles in aqueous media. Meanwhile, the adsorption can be used to isolate the graphene sheets with controlled thickness in the density gradient ultracentrifugation (DGU) method (Blanch et al., 2010). In next scheme (Fig. 
1) some usual surfactant for dispersion and preparation of graphene sheets are presented.
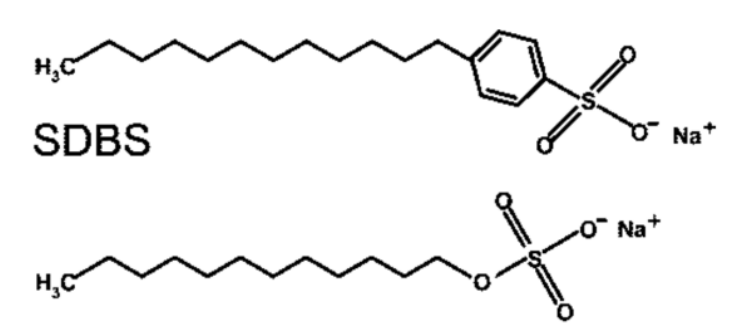

SDS
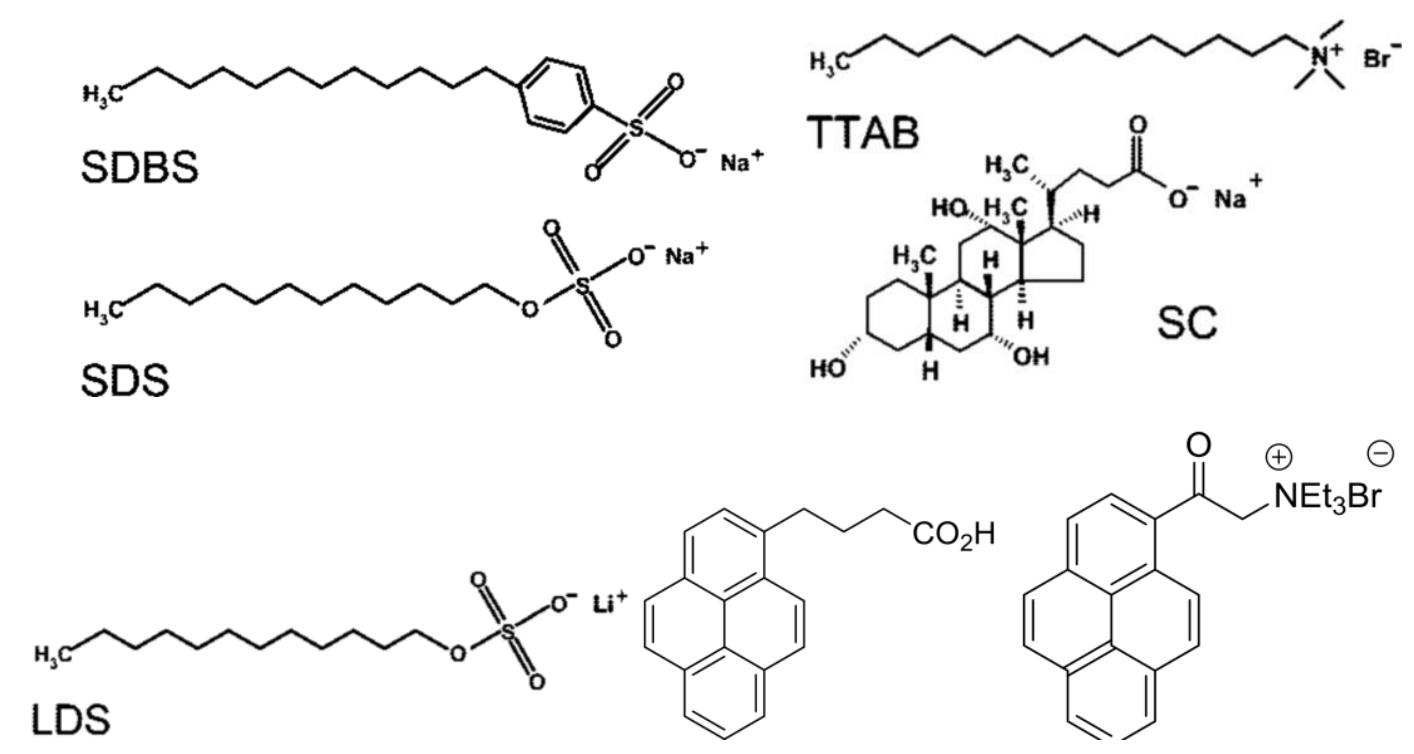

Fig.l some usual surfactant for dispersion and preparation of graphene sheets

Javadian, and Khosravian in 2018 studied Self-Assembly Morphology of Fatty Acid on Graphene Synthesized by Surfactant Assisted LPE by A Joint MD, SAPT(DFT) and Experimental Study. They investigated different factors. such as surface density, environment $\mathrm{pH}$, substrate size and number of layer. The results show that the decrease in $\mathrm{pH}$ transmutes the nature of the classical electrostatic interaction between the surfactants from repulsion to attraction leading to a decline in the stability of the colloidal systems. The morphology of self-assembly on the graphene surface and the factors tailoring the morphology were surveyed in light of classical molecular dynamic (MD) and symmetry-adapted perturbation theory (SAPT) have applied Docosahexaenoic acid (DHA) fatty acid to disperse graphite (Javadian and Khosravian, 2018).

Two important features which characterize surfactants, namely adsorption at interface and self-accumulation into supramolecular structures, are advantageously used in processing stable colloidal dispersions. The adsorption of surfactants onto inorganic and organic surfaces usually depends on the chemical characteristics of particles, surfactant molecules and solvent (Vaisman et al., 2006). Surfactant selfassembly structures on carbon surfaces have been extensively studied by several 
research groups (Wu and Yang, 2012; Xu et al., 2010).

Haar and Coworkers developed A Supramolecular Strategy to Leverage the Liquid-Phase Exfoliation of Graphene in the Presence of Surfactants. They also investigated the Role of the Length of Fatty Acids. Here, a fundamental understanding on a straightforward supramolecular approach for producing homogenous dispersions of unfunctionalized and non-oxidized graphene nanosheets in four different solvents is attained, namely $\mathrm{N}$-methyl-2-pyrrolidinone, $\mathrm{N}, \mathrm{N}$-dimethylformamide, ortho dichlorobenzene, and 1,2,4-trichlorobenzene (Haar et al., 2016).

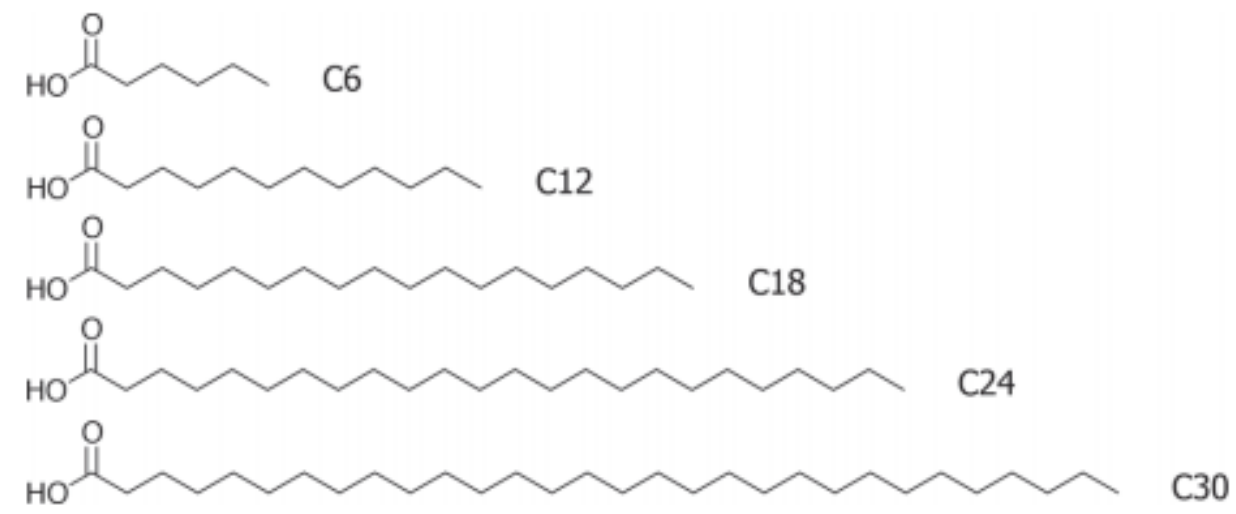

Fig.2 Chemical structures of investigated carboxylic acid derivatives by Haar and coworkers.

The addition of the C24 and C30 molecules reduces significantly the amounts of thick graphitic flakes (Fig.2)

Narayan and coworkers studied Perylene tetracarboxylate surfactant assisted liquid phase exfoliation of graphite into graphene nanosheets with facile redispersibility in aqueous/organic polar solvents. non-covalent surface chemistry between graphene and perylene tetracarboxylate (PTCA) aromatic semiconducting surfactant was studied by this research group. Significantly, pure aromatic semiconducting nature of surfactant without dielectric moiety ensures tight electrical contact among graphene sheets in thin films. The approach exploiting the simple molecular design of aromatic charged surfactants for graphene exfoliation holds a great prospect for solution processed graphene based nanomaterials and devices (Nayaran et al., 2017. 
The strategy of this research is showed in Figure. Graphite flakes are first noncovalently functionalized with PTCA in water via $\mathrm{p}-\mathrm{p}$ stacking interactions. Subsequent low power sonication releases exfoliated graphene sheets stabilized by electrostatic repulsion given by adsorbed PTCA molecules.

(a)
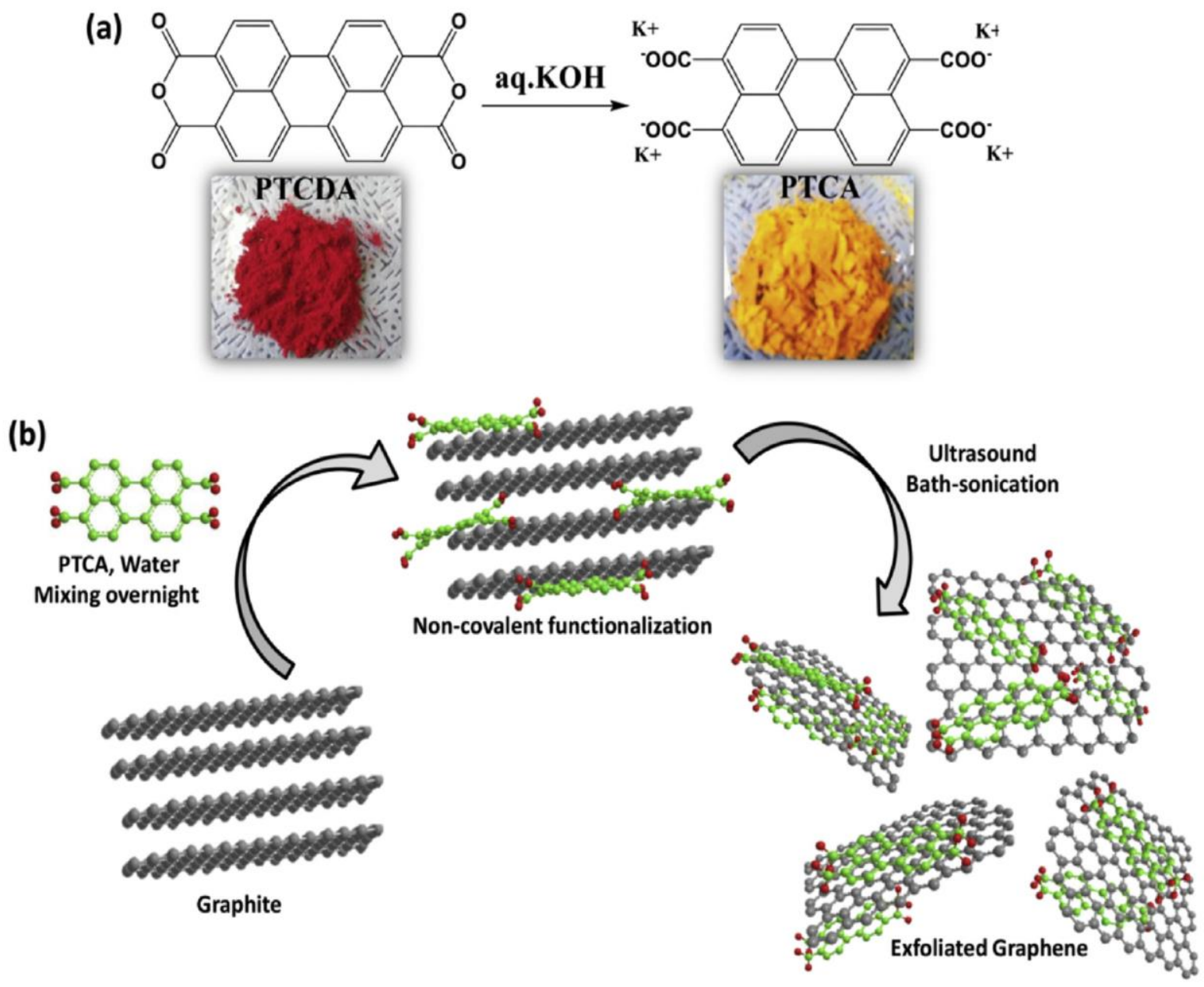

Fig.3 The diffirent step of NAYARAn and coworkers. (a) Synthesis of PTCA surfactant from PTCDA precursor. (b) Schematic process for PTCA assisted liquid phase exfoliation of graphite.

Nayaran and coworkers (2017) proposed the following schem (Fig. 4) for mechanism of electronic interaction between graphene and PTCA Surfactant in the non-covalent structure. 


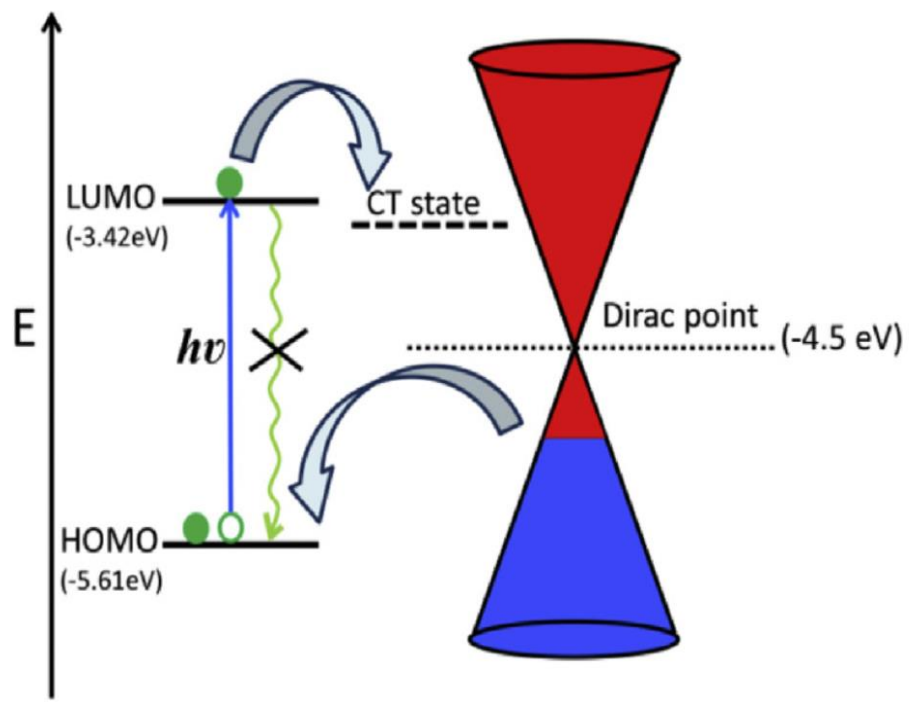

\section{PTCA Graphene}

Fig.4 mechanism of electronic interaction between graphene and PTCA in the non-covalent Structure

Ahmadin and coworkers in 2019 used Computational Methods for Graphite delamination using Anionic Surfactants to produced pgraphene. They compared the capability of two different anionic surfactant sodium 4-actyloxybenzoate and Sodium Laurate. Gaussian calculation was applied in order to perform molecular dynamics analysis, first, (the minimum) force that each atom imposes to other atoms was calculated. The optimal structure showed that the presence of benzene, ether and carboxylic groups lead to facilitate the entry of surfactants into the plates and is a factor for starting the separation of grapheme sheets. The longer the surfactant sequence is the desire and ability to separate the plates by surfactant increase. The presence of an aromatic group in surfactant causes $\pi-\pi$ interaction among the surfactants and graphene sheets, and makes the placement of the plates in parallel with the plate of the benzene ring and also creates distance in flat graphene sheets (fig. 5) (Ahmadin et al., 2019).

This research group also determined the HOMO and LUMO arbital of the System of Interaction of Surfactant and graphene sheets. In figure 6, the Laurate surfactant and graphene system is showed. 


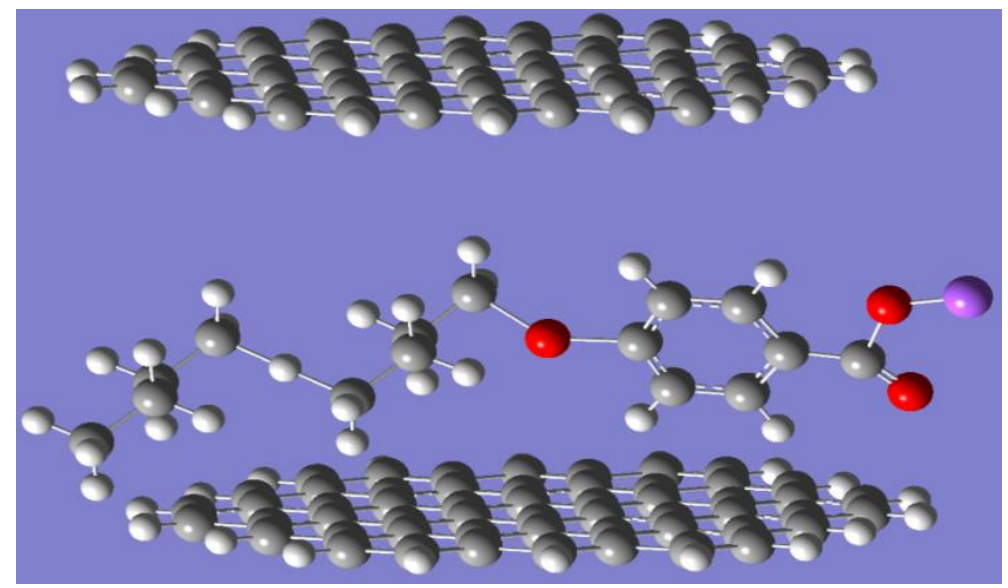

Fig.5 Gaussian view schem of dynamic modeling of surfactant and graphen sheet interaction by Ahmadin and coworkers.
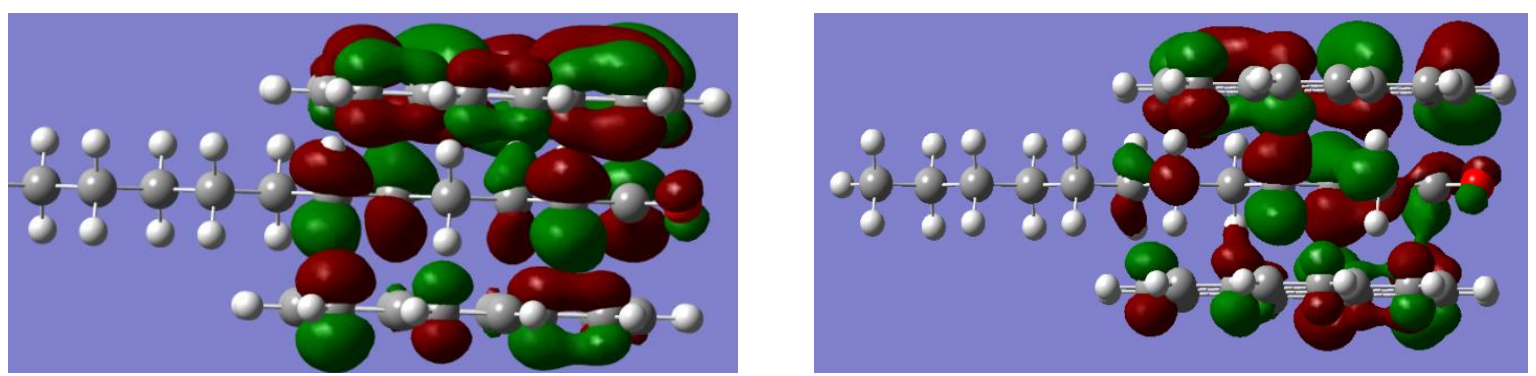

Fig.6 Double layer graphite HOMO ( Left) an LUMO (right) orbital in the presence of sodium laurate surfactant

In Figure 7, the electrostatic interaction of graphite plates and sodium laurates surfactant is presented. In red areas, negative charge accumulation is more than white and blue areas and on the other hand, the negative charge accumulation of graphene sheet and anionic surfactant causes electrostatic repulsion and, consequently, increases the gap between graphite layers (Ahmadin et al., 2019).

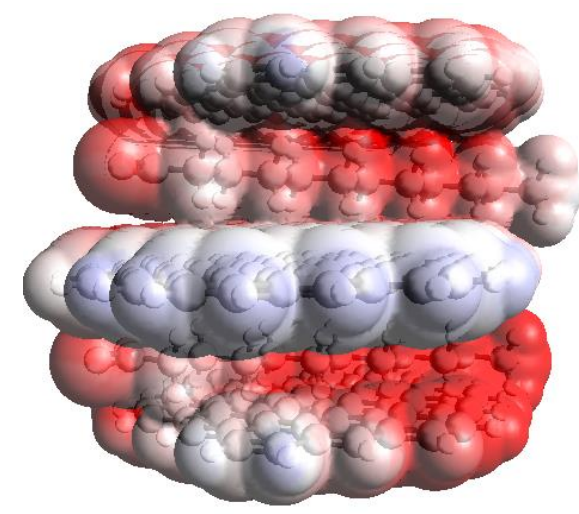

Fig.7 Electrostatic interaction of graphite plates and parallel sodium laurate surfactant 
Heard and coworkers in 2019 studied the Rational Design of Aqueous Graphene Dispersants. This study presents preliminary experimental data suggesting that sodium 4-(pyrene-1-yl)butane-1-sulfonate (PBSA), 5, an analogue of sodium pyrene-1sulfonate (PSA), l, enhances the stability of aqueous reduced graphene oxide (RGO) graphene dispersions (Heard et al., 2019). The strategy of Heard and coworkers is showed in Fig.8.

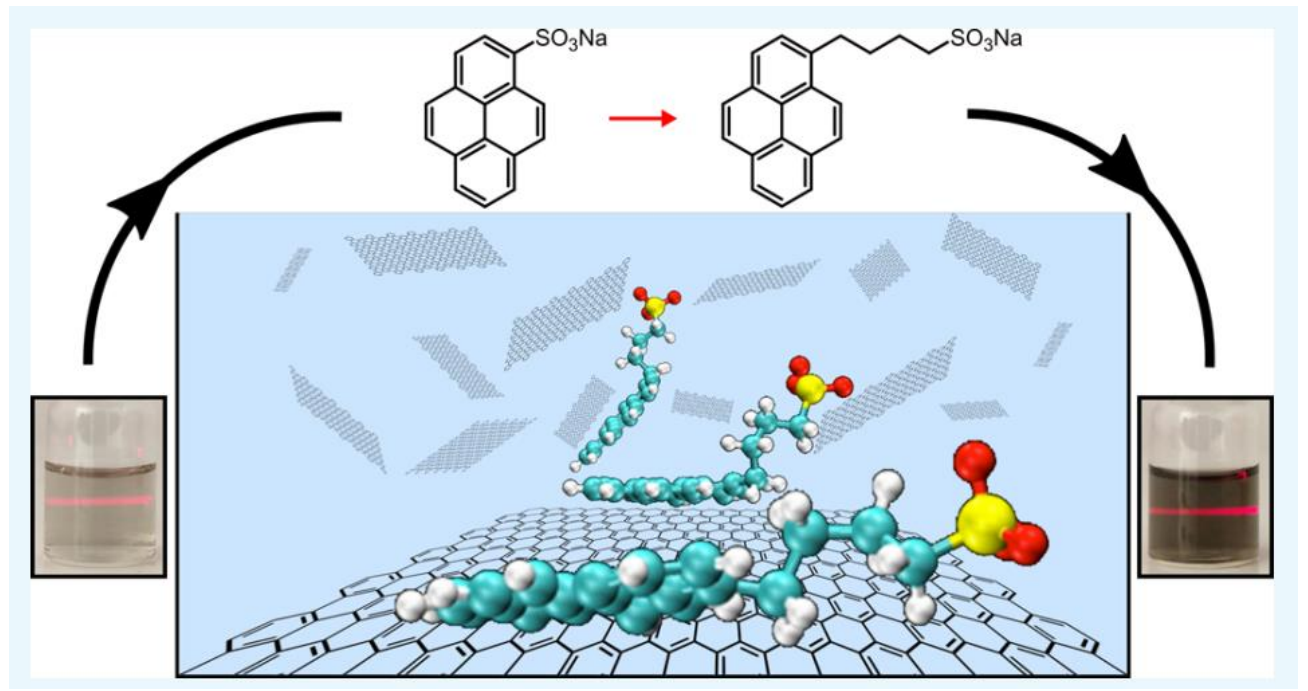

Fig.8 The strategy of Heard and coworkers

Zhang et al. (2018) investigated the direct exfoliation of graphite in graphene aqueous solution using a new surfactant derived from motor oil. This study presents a new classification of dispersion factors for graphene, which helps the process of exfoliating in water with high-concentration and stabilization of graphene plates against the reaccumulation.

Monajjemi (2017) in a research investigated the liquid phase exfoliating (LPE) of graphite for graphene. In this study, by ab initio study, they showed that sulfone groups in surfactants are most effective for any dispersion in the LPE process.

Haar and coworkers in 206 developed Liquid-Phase Exfoliation of Graphite into Single- and Few-Layer Graphene with $\alpha$-Functionalized Alkanes. Report the exfoliation of graphite in $\mathrm{N}$-methyl-2-pyrrolidinone, in the presence of heneicosane linear alkanes terminated with different head groups. These molecules act as stabilizing agents during exfoliation. The efficiency of the exfoliation in terms of the 
concentration of exfoliated single- and few-layer graphene flakes depends on the functional head group determining the strength of the molecular dimerization through dipole-dipole interactions. A thermodynamic analysis is carried out to interpret the impact of the termination group of the alkyl chain on the exfoliation yield (Haar et al., 2016).

Sun and Yang in 2014, used Molecular simulation by classical molecular dynamics has been performed to study the adsorption self-assembly of sodium dodecylbenzene sulfonate (SDBS) on nanosized graphene sheets. They found Under higher surfactant concentration, multilayered micelles can be formed on the graphene surfaces. Also by using MD calculation they probed unique supramolecular morphology with SDBS adsorption on multilayer graphene nanosheets. also simulated the potential of mean force (PMF) between two nanoscale graphene sheets covered by SDBS surfactants in order to understand the interaction mechanism in the SDBS-based graphene dispersion and stabilization (Sun et al., 2014).

Side and front views of representative simulation snapshots of their calculation for the self-assembly of SDBS surfactants absorbed on graphene sheets are showed in fig. 8 .
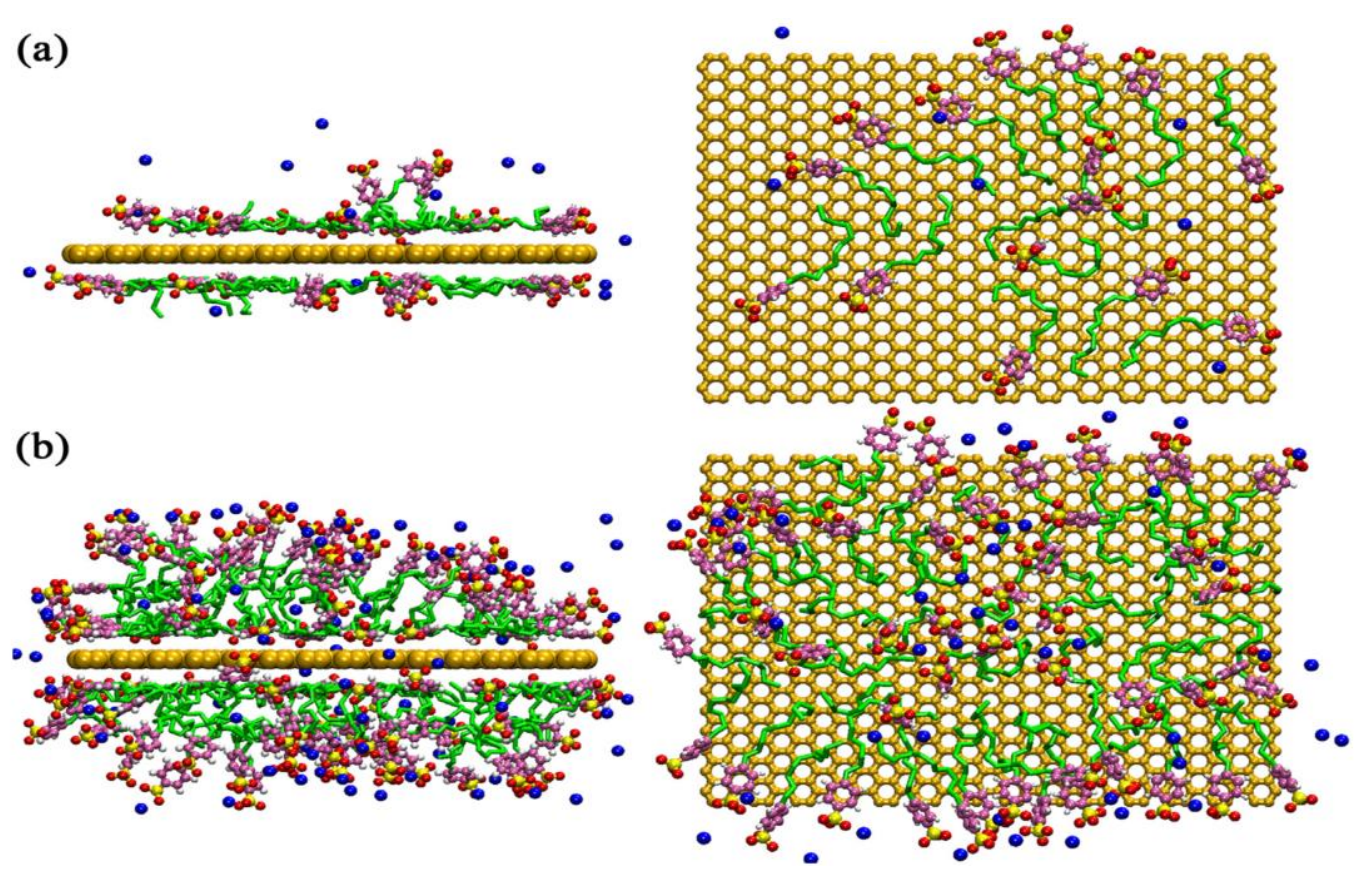

Fig.8. Side and front views of representative simulation snapshots for the self-assembly of SDBS surfactants absorbed on graphene sheets: (a) at low surface coverage; (b) at high surface coverage. Color code: green for $\mathrm{CH} n$ groups; purple for carbon atoms in benzene rings; yellow for sulfur atoms; red for oxygen atoms; blue for sodium counterions; orange for carbon atoms in graphene. 
Lomeda et al. reported diazonium functionalization of surfactant-wrapped chemically converted graphene sheets (Lomeda et al., 2008).

\subsubsection{Graphite Oxidizing}

Graphene layers are held together by van der Waals forces in graphite; The most common approach to of producing graphene from graphite involves oxidizing the graphite to produce graphite oxide, which may then be exfoliated to yield dispersions of graphene oxide. While the graphitic nature of the resulting nanosheets is highly compromised by oxidation, leading to loss of conductivity, reduction by chemical, $2 \mathrm{~b}, 5$ thermal,6 or electrochemical7 treatment results in partial recovery of the graphitic character (Stankovich et al. 2006, 2007). Graphene oxide (GO) may subsequently be chemically or thermally treated to remove the covalent functional groups and produce reduced graphene oxide (rGO).

Sabziparvar and coworkers investigated that $\mathrm{Ca}^{2+}$ cation effect on graphene oxide sheets. They found Ca2+ cation is more detrimental in case of GO agglomeration in the cementitious environment, compared to the monovalents Dispersion of GO in water mainly occurs via its oxygen functional groups including hydroxyl and epoxide functional groups. They found in mild alkali media, an increment in $\mathrm{pH}$ from 7 to about 10.9 causes more ionization and electrostatic repulsion, which leads to better dispersion. However, at high alkali media with pH larger than 10.9 GO dispersion undergoes reduction when $\mathrm{pH}$ increases, because GO loses the most of its functional groups and then will agglomerates (Sabziparvar et al., 2019).

Lomeda and coworkers developed a new methos as Diazonium Functionalization of Surfactant-Wrapped Chemically Converted Graphene Sheets. It was obtained from reduction of graphene oxide with hydrazine were functionalized by treatment with aryl diazonium salts. Their resuls showed The resulting functionalized nanosheets disperse readily in polar aprotic solvents, allowing alternative avenues for simple incorporation into different polymer matrices (Lomeda, 2008).

The functionalize Graphen with high amounts of varying aryl addends, allowing these nanosheets to be solubilized in organic solvents. This strutegy may prove to be useful in the area of composites, especially in the use of these 2-D structures as 
reinforcing agents where intimate interfacial bonding between the host and the structural modifier is critical (Fig. 9)

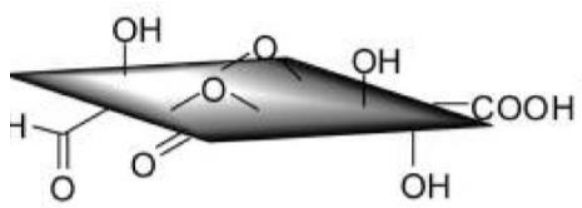

SDBS-wrapped GO
1. $\mathrm{N}_{2} \mathrm{H}_{4} \bullet \mathrm{H}_{2} \mathrm{O}, \mathrm{pH} 10$ $80^{\circ} \mathrm{C}, 24 \mathrm{~h}$

2.

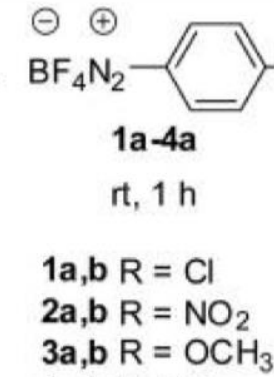

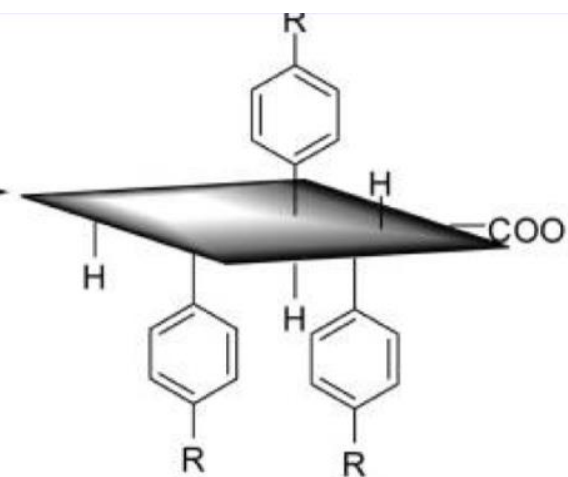

$1 b-4 b$

Fig.9. SChem of methods of Lomeda and coworkers by Starting with SDBS-Wrapped GO, Reduction, and Functionalization of Intermediate SDBS-Wrapped hemically converted graphen (CCG) with Diazonium Salts

Stankovich et al. chemically modified the graphite oxide using phenyl isocyanate in $\mathrm{N}, \mathrm{N}^{\prime}$-dimethylformamide (DMF). The grafting of long alkyl chain or sixarmed poly- (ethylene glycol) on the graphite oxide surface through amideformation with the carboxyl groups was reported (Stankovich et al., 2006, 2007).
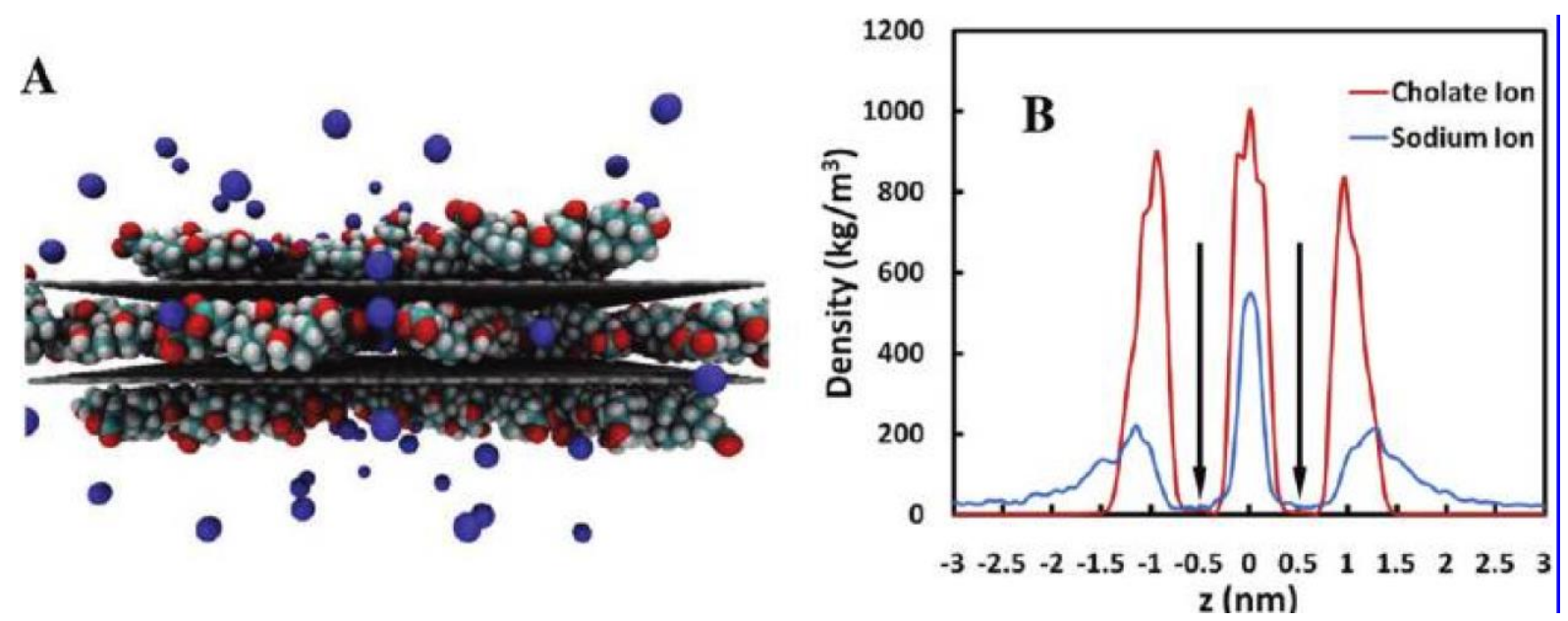

Figure 10. (A) Postequilibrium simulation snapshot of the metastable bilayer grapheneSC assembly at an intersheet separation of $d=1.05 \mathrm{~nm}$, showing a single layer of cholate ions and a sodium counterion wall confined between the two graphene sheets. Water molecules are not shown for clarity. The color code is the same as in Figure 1. (B) The simulated density profiles of the cholate ions and the sodium counterions along the z-axis, showing a single layer of cholate ions and a sodium counterion wall (both peaked at $z=0 \mathrm{~nm}$ ) being confined between the two graphene sheets. (Lin et al, 2011). 


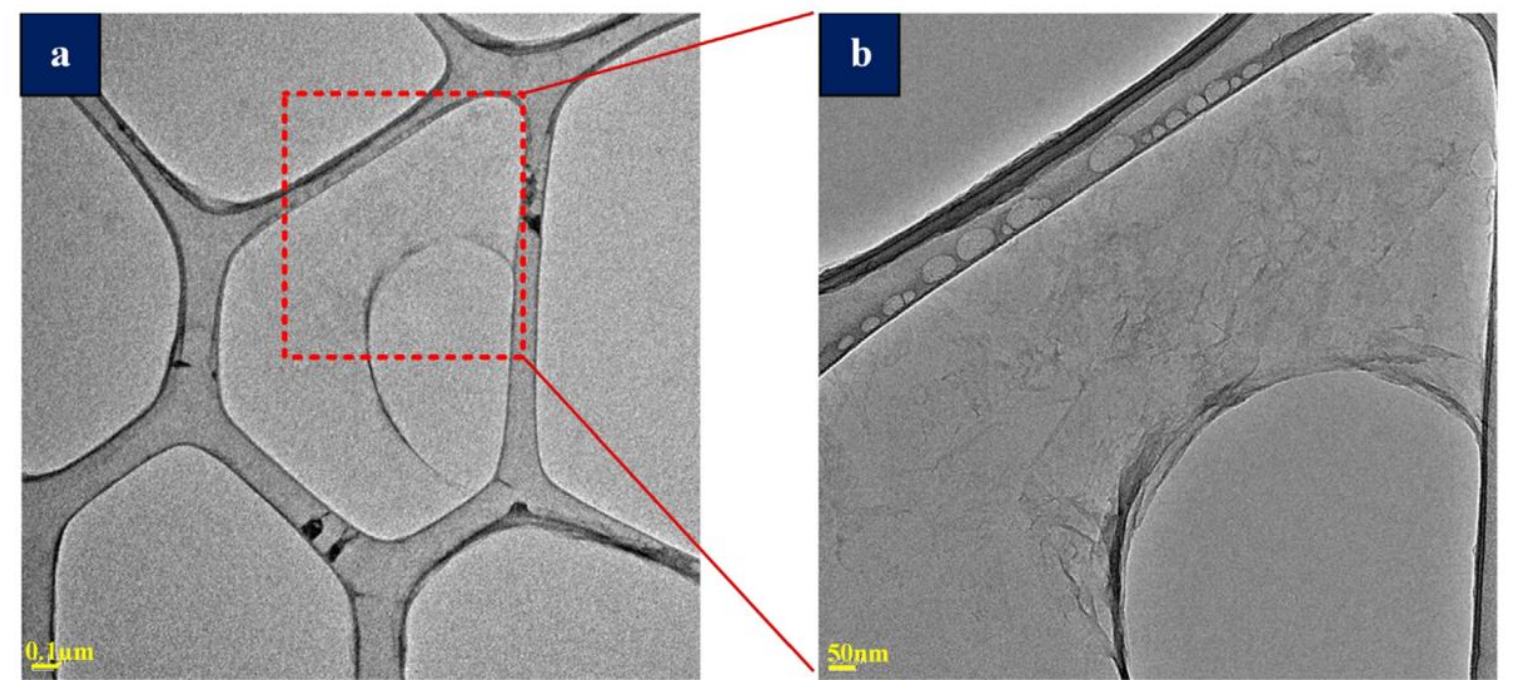

Fig.ll TEM image of as-received GO nanosheets, (a) low magnification and (b) high magnification.

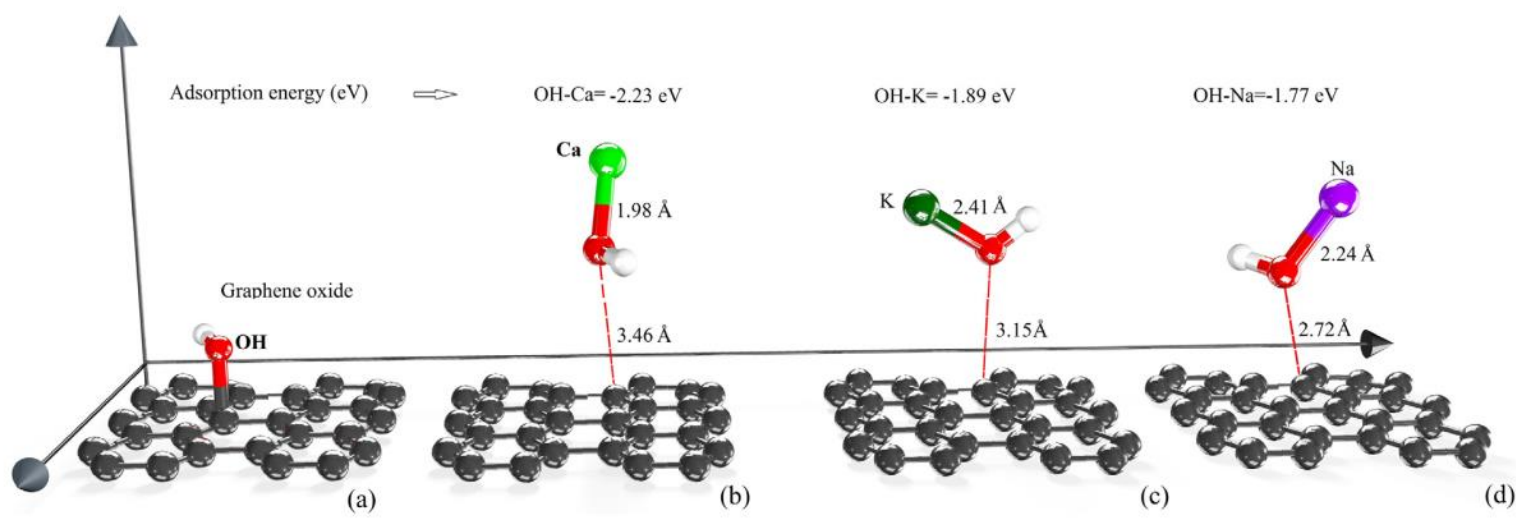

Fig. 12. Hydroxyl group location (a) before adsorption and after adsorption of (b) calcium, (c) potassium, and (d) sodium.

$\mathrm{OH}$ group detachment and physical interaction between graphene and calcium hydroxide could be found. Fig.12(a) shows the electron density difference before the adsorption of calcium on the GO, which represents a covalent bond between the hydroxyl and GO surface and no electron exchanging between calcium and GO. However, after the adsorption (Fig. 12(b) and (c)), calcium ion disrupts CAO covalent bond by transferring the charge to $\mathrm{OH}$ and making an electrostatic interaction. Through this mechanism, the hydroxyl group is being located at a relative location respect to GO surface in which a vdW physical interaction creates and eventually diminish polarity of GO surface (Lin et al., 2011). 

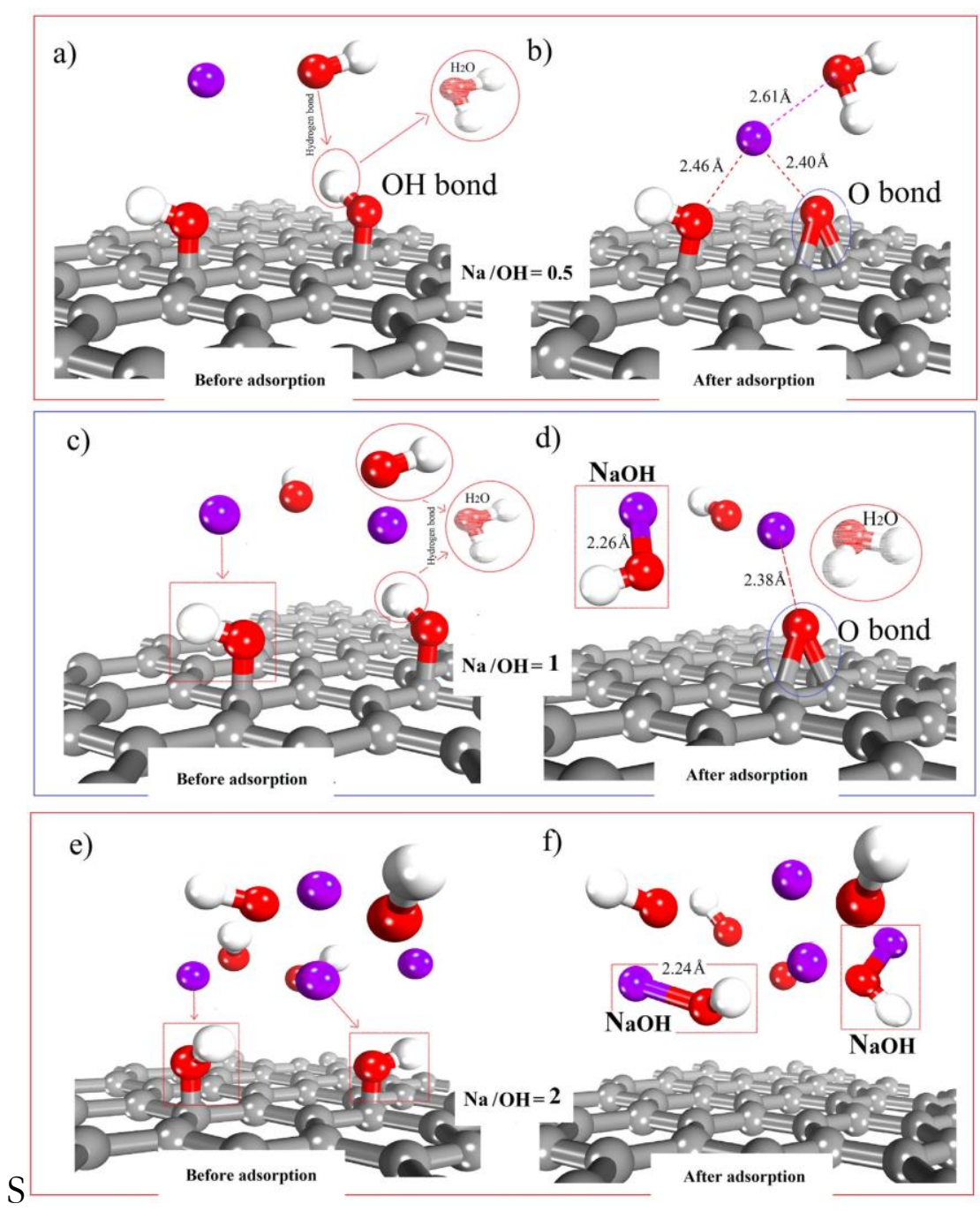

Fig.13. Interaction of $\mathrm{GO}$ with $\mathrm{NaOH}$ at different ratios of sodium to the hydroxyl group of $\mathrm{GO}$; (a), (b) $\mathrm{Na} / \mathrm{OH}=0.5$, (c), (d) $\mathrm{Na} / \mathrm{OH}=1$, and (e), (f) Na/OH =2.

\subsubsection{Self-Assembly Approach for Exfoliation of Graphite}

But Zhang research geoup a new tempelate base strategy as Based on a Confined Self-Assembly Approach for production single seet graphen. The three-step procedure of this strategy is showed in Figure 5. A special structure-directing surfactant containing a pyrrole moiety is used to construct lamellar mesostructured silica. Since polypyrrole is an ideal carbon precursor to form raphite, this surfactant can serve simultaneously both as the structure-directing agent and as the carbon source. During the formation of the lamellar silica framework, the pyrrole moieties could be densely packed in a controlled fashion within confined 2D spaces between silica layers, providing the prerequisite for quantitative production of isolated graphene sheets after 
carbonization. After the in situ polymerization of the organized pyrrole moieties using $\mathrm{FeCl} 3$ as oxidant, the resulting polypyrrole nanosheets were individually transformed into single-layer graphene sheets in N2 atmosphere (Fig. 14), for which the residual iron salts from the polymerization process were directly employed as catalyst for the conversion (Zhang et al., 2018).

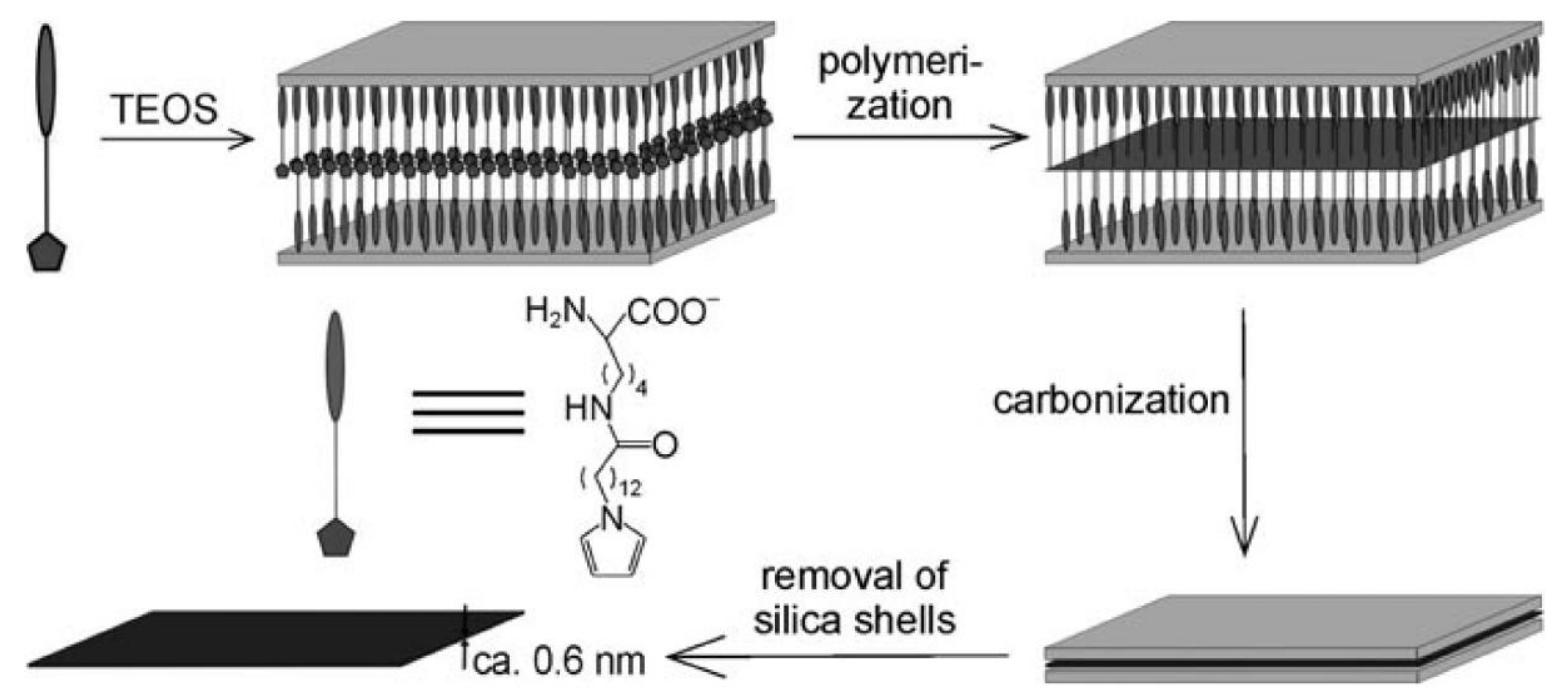

Figl4 Schem of Zhang'S strategy for fabrication of pure single-layergraphene with a thickness about. $0.6 \mathrm{~nm}$. TEOS=tetraethoxysilane

Lin and coworkers, graphene-based electronic and optical devices requires synthesis methods to either control the number of layers to enrich AB-stacked bilayer or trilayer graphene or control the extent of functionalization of monolayer graphene. Over the past decade research efforts devoted to graphene fabrication (Lin et al., 2011).

Poorsargol and coworkers (2014) developed an method of Dispersion of Graphene using Surfactant Mixtures. They investigated Experimental and Molecular Dynamics Simulation for The capability of sodium dodecyl sulfate (SDS) and cetyltrimethylammonium bromide (CTAB), cationic-rich and anionic-rich mixtures for dispersion of graphene nanosheets in an aqueous medium. In MD simulation The $\zeta$-potential about surfactant mixture-graphene assemblies was estimated using Poisson's theory. The $\zeta$-potential about surfactant mixture-graphene assemblies was estimated using the results of MD simulation and Poisson's theory the design and selection of appropriate surfactants, the optimization of the process and the 
improvement of graphene dispersion in aqueous solutions of surfactants. Interactions between two surfactant mixture-graphene assemblies were evaluated through calculating the potential of mean force (PMF), and it was found that increasing surfactant surface coverage would lead to an enhanced repulsive barrier of PMF Using surfactant mixtures for dispersing graphene nanosheets is promising. Moreover, MD simulations were used to examine surfactant mixture assemblies' structure on graphene and explain the experimental results, which showed that the random adsorption model first changes to the monolayer model and then the hemispherical model with an increased surfactant concentration. novel method based on the controlled electrochemical exfoliation of graphite in aqueous ammonium sulfate electrolyte to produce graphene in large quantities and with outstanding quality.

Common challenges, including controlling the surface morphology, reducing the turbostratic layering, and enhancing the dispersion stability (Lin et al., 2011). The latter, solution-phase method offers several significant advantages since it: (i) utilizes inexpensive and readily available graphite flakes, (ii) does not require transferring the graphene from the growth substrate, (iii) employs existing technologies (e.g., sonication and centrifugation) for scaled-up large volume processing, and (iv) allows solution-phase chemical functionalization of graphene.

\subsubsection{Electrochemical exfoliation}

Electrochemical exfoliation has recently emerged as a promising strategy for producing graphene on an industrial scale with high efficiency, at low cost, and in an environmentally friendly manner (Bunch et al., 2007; Yang et al., 2015; Liu et al., 2008). Either cathodic or anodic potentials are able to drive guest ions into graphitic layers which promotes the structural deformation of a graphite working electrode. Organic Radical-Assisted Electrochemical (Yang et al., 2015; Xia et al., 2013). Morphology ographen obtained by electrochemical methods were investigated by researchers for tha capability of its for electrical and mechanical purpose (Eredia et al., 2017).

A facile approach to disperse graphene in aqueous solution is described (Li et al., 2008). Graphene can be prepared via top-down approach from graphite through physical exfoliation ("peel-off")l and chemical exfoliation. The latter method generally 
produces a large-scale amount up to grams. However, chemical exfoliation gives graphite oxide which contains lots of hydrophilic oxygencontaining groups such as carboxyl, hydroxyl, and epoxide (Zu and Han, 2009).

\subsubsection{Polymeric and copolymeric hydrogels}

$\mathrm{Zu}$ And Han in 2009 produced Graphene Sheets Formation of Supramolecular Hydrogel and Stabilized by Pluronic Copolymers: Proposed strategy of the formation hydrogel by Copolymers for Production graphene sheets is showed in next figure. utilizing the dual roles of Pluronic copolymer in dispersing graphene in aqueous solution and forming supramolecular hydrogel with R-CDs through the penetration of PEO chains into the cyclodextrin cavities, (fig. 15). They developed a facile and effective method to hybridize the well-dispersed graphene into a supramolecular hydrogel ( $\mathrm{Zu}$ and Han, 2009).
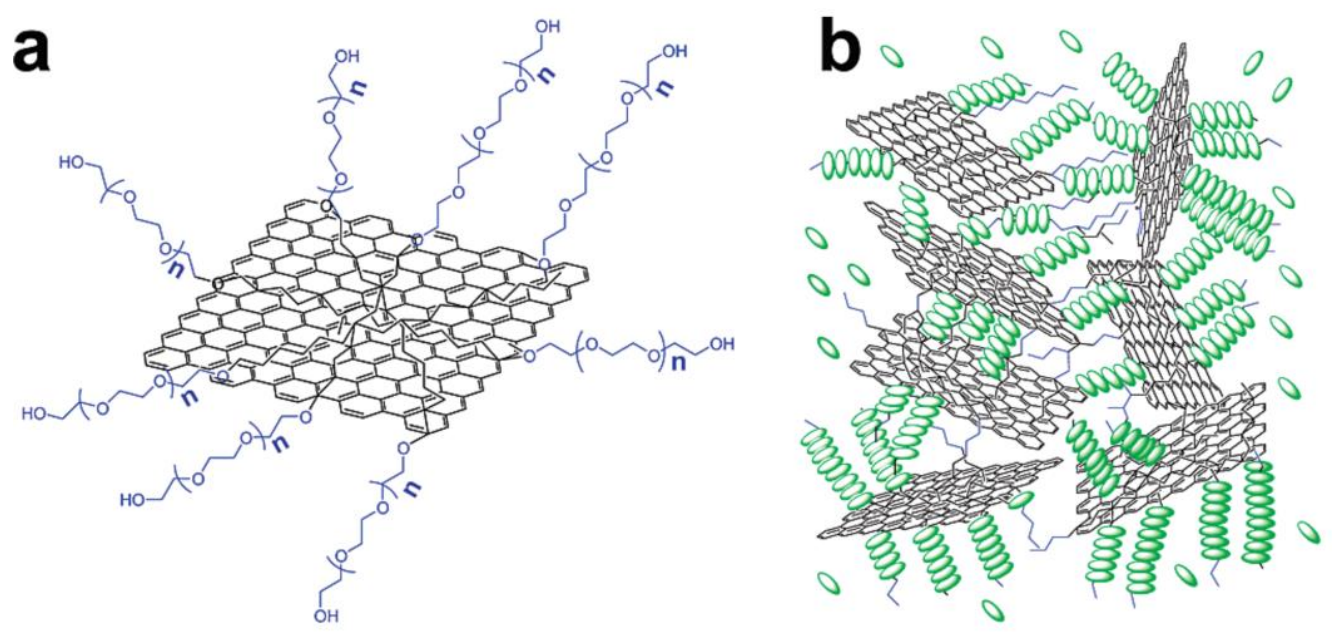

Fig.15. Proposed structure of the copolymer coated graphene (a) and supramolecular well-dispersed graphene sheet containing hybridhydrogel (b).

\subsubsection{Ionic Liquid}

Novel ionic liquids (ILs) were designed and synthesized to contain aromatic groups for Direct exfoliation of graphene (Porsargol, 2014) Ionic liquids (ILs) are organic molten salts with melting point temperatures below $100{ }^{\circ} \mathrm{C}$, which have been 
used extensively as solvents. ILs are non-volatile, thermally stable, nonflammable, recyclable, and capable of dissolving a range of solutes. Furthermore, their properties such as miscibility and viscosity can be tuned via chemical changes to the cation or anion (Zheng et al., 2011; Ravula et al., 2015). Additionally, ILs are attractive because of their status as green solvents due to their low vapor pressures and ease of recycling, in contrast to common organic solvents.

ILs can disperse graphene directly (Wang et al., 2010). The mechanisms behind ILgraphene interactions are just beginning to be understood (Porsargol, 2014).
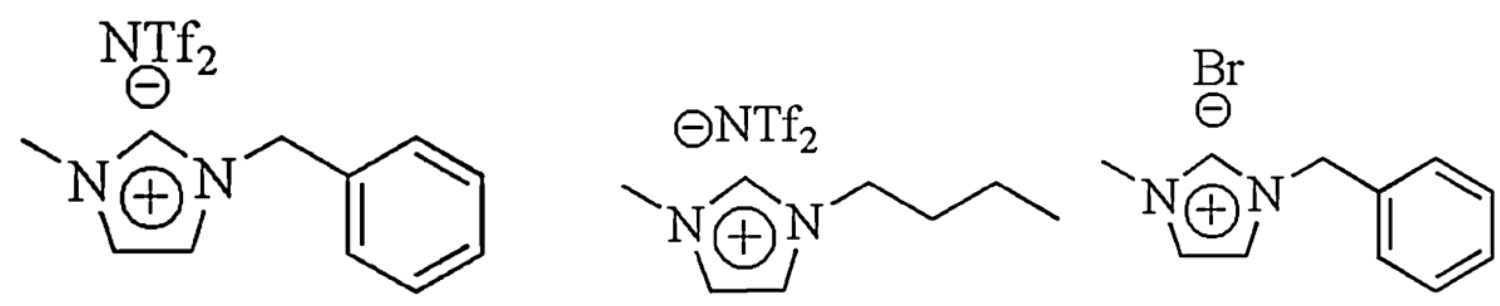

Fig.16. Usual ionic liquids for dispersion of graphene.

Bari and coworkers, used ionic liquids with aromatic groups for direct exfoliation of graphene. Novel ionic liquids (ILs) were designed and synthesized to contain aromatic groups on the imidazolium cation that non-covalently interact with graphene surfaces. In Figure 17 the schematic strategy of this research group is showed.

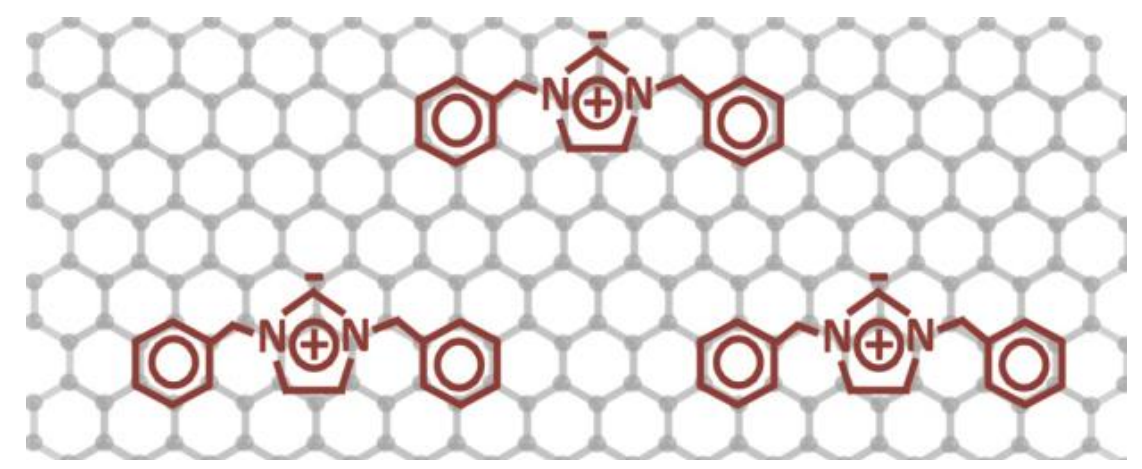

Fig.17. schematic of the strategy of Bari and coworkers

They used Density functional theory (DFT-D3) calculations used for predictive modeling of IL design for optimal graphene dispersions. Interaction of Graphene and IL computed at the PBE-RI/TZVPP level is showed in next figure. In their results IL-4 
with two phenyl groups was the most effective one in stabilizing the graphene dispersion with a high yield of $5.8 \mathrm{mg} \mathrm{mL}-1$. the dispersion of graphene in ILs at high concentrations without covalent functionalization or additive stabilizer was the result of their investigation. These preliminary computational calculations suggest that the addition of $\pi$-stacking capable substituents will increase the adsorption of the ionic liquids on the graphene surface with a possible favorable effect on the exfoliation and stabilization processes(Fig. 18) (Bari et al., 2014).

a) $\Delta \mathrm{E}=-27.4 \mathrm{kcal} / \mathrm{mol}$

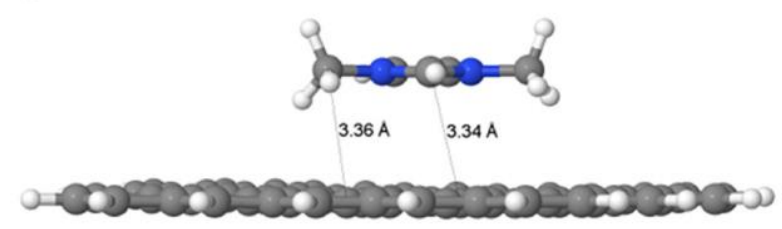

b) $\Delta \mathrm{E}=-28.7 \mathrm{kcal} / \mathrm{mol}$

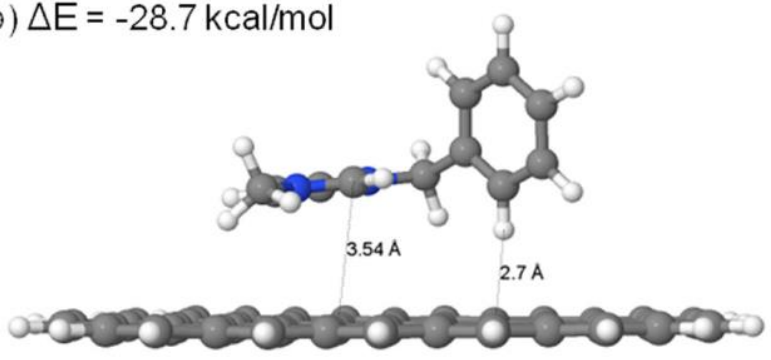

c) $\Delta \mathrm{E}=-30.6 \mathrm{kcal} / \mathrm{mol}$

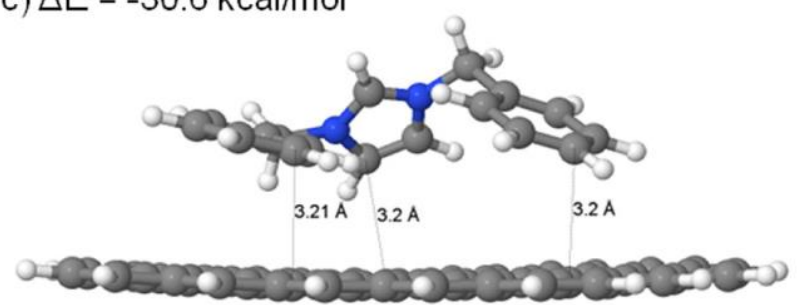

d) $\Delta \mathrm{E}=-11.7 \mathrm{kcal} / \mathrm{mol}$

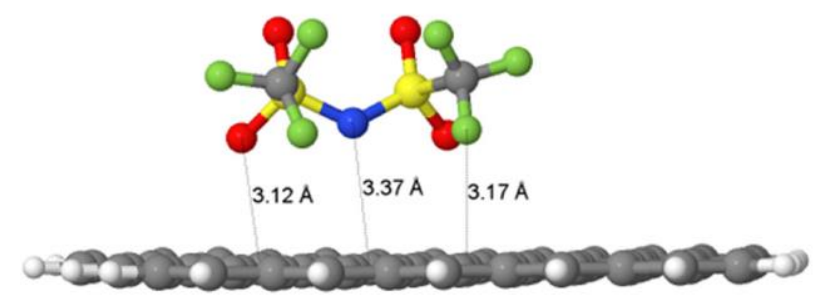

Fig. 18. Graphene and IL interaction computed at the PBE-RI/TZVPP level:(a) [ClClim]+ cation and graphene, (b) IL-1 [BnzClim]+ cation and graphene, (c) IL-4 [(Bnz)2im]+ and graphene, and (d) [NTf2]- anion and graphene. The two additional aromatic rings on IL-4 provide an increased interaction with graphene relative tostructure (a). Shorter distances between the cation and graphene can be observed and also a slight curvature of the carbon sheet as an effect of stronger - interactions (Liu et al., 2008). 


\subsubsection{Other Delamination strategy}

High pressure homogenizer combines surfactant were used by Peukert's research group for graphene prodiction from graphite. principle of graphite delamination by high pressure homogenizer (HPH). The suspension is pumped through a nozzle and released into an expansion chamber. A counter pressure can be applied to the suspension by closing the valve after the expansion chamber. HPH devices are commonly used in food industry, cell disintegration 24 , emulsification 25 , 26 or dispersion of active pharmaceutical ingredients.27,28 Recently, HPH devices were employed for graphene production by exfoliation of thermally reduced graphite oxide (Nacken et al., 2015).

The Resulted graphene dispersions were used for manufacturing graphene films by printing techniques or for preparation of graphene nanocomposites with superior mechanical and electrical properties (Appel et al., 2012).

Chiesielski and SAmori in 2014 developed a simple method for this purpose as Graphene via sonication assisted liquid-phase exfoliation (Ciesielski and Samori, 2014).

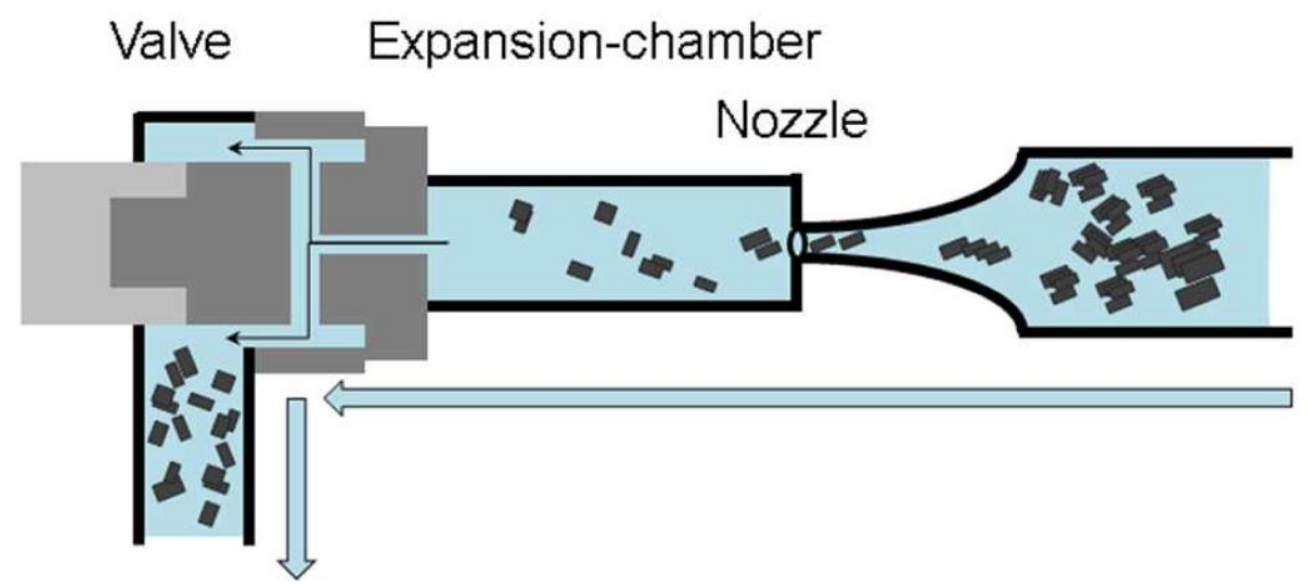

Fig. principle of graphite delamination by HPH.

1.2. Thermodynamic and electrostatic equation of Graphene sheets

\subsection{1-Total Graphene Dispersion Stability}

To utilize the kinetic model described above to calculate the time-dependent number concentration of various graphene layer 


$$
N_{\text {total }}(t)=\sum_{i=1}^{\mathrm{M}} N_{i}(t)
$$

\subsubsection{Interactions between two parallel graphene sheets}

To assess the optimum and appropriate interactions between two parallel graphene sheets that coated with surfactant, the PMF was evaluated through the numerical integration (the trapezoidal method) of the interaction forces needed to separate two parallel graphene sheets fixed at different intersheet separations d (along the $z$-axis of the simulation box) from $\mathrm{dl}=0.7 \mathrm{~nm}$ to $\mathrm{d} 2=2.0 \mathrm{~nm}$. The PMF between two graphene sheet covered by pure SDS and CTAB surfactants was also calculated for comparison. The PMF is found through integrating constraint force $\left(\mathrm{F}_{\mathrm{C}}(\mathrm{r})\right)$ as follows:

$$
P M F(r)=\int_{d 1}^{d_{2}} F_{C}(r) d r
$$

To calculate the average total forces exerted on both graphene sheets $\left(\mathrm{F}_{\text {tot }}\right)$ :

$$
\begin{gathered}
F_{C}(d)=\frac{1}{2}\left\langle\vec{d}_{v} \cdot\left(\vec{F}_{t o t}^{1}\left(\vec{d}_{1}\right)-\vec{F}_{t o t}^{2}\left(\vec{d}_{2}\right)\right)\right\rangle \\
\vec{d}_{v}=\frac{\left(\vec{d}_{1}-\vec{d}_{2}\right)}{\left|\vec{d}_{1}-\vec{d}_{2}\right|}
\end{gathered}
$$

where $d_{v}, d_{1}$ and $d_{2}$ are the unit vector and the position of center of mass of graphene sheets 1 and 2, respectively. To find the PMF, a series of initial configurations were constructed by positioning two parallel graphene sheets coated with surfactants at different intersheet separations.

In 2008, Bergin et al. combined experiment and thermodynamic modeling to show that the enthalpy of mixing of nanotubes per volume of solvent is given by. surface energy of graphite is similar to that of carbon nanotubes, it might be possible to exfoliate graphite to give graphene in certain solvents:

enthalpy of mixing of graphite: per volume of solvent is given by

$$
\Delta H_{\text {mix }} / V \approx 4\left(\sqrt{E_{S, N T}}-\sqrt{E_{S, S o l}}\right)^{2} \phi / D
$$

Here where $\varphi$ is the dispersed nanotube volume fraction, D is the dispersed 
graphite diameter, and $E_{S, N T}$ and $E_{S, S o l}$ are the graphite and solvent surface energies, respectively. This suggested successful solvents to be those with surface energy close to that of the graphite. he maximum dispersible concentration of graphite in solvents is given by

$$
\phi \approx K^{\prime} \exp \left[-\frac{\bar{v}}{R T} \frac{\partial\left(\Delta H_{\text {Mix }} / V\right)}{\partial \phi}\right]
$$

here $\mathrm{K}_{0}$ is a constant and vh is the molar volume of rods. Applying to nanotubes by mixing two above equation:

$$
\phi \approx K^{\prime} \exp \left[\frac{\pi D L}{4 E_{S, N T} k T}\left(E_{S, N T}-E_{S, S O}\right)^{2}\right]
$$

here $\mathrm{L}$ is the mean nanotube length. This expression represents a Gaussian function when $\varphi$ is plotted versus the solvent surface energy.

\subsubsection{Electrostatic Potential of Surfactant graphene system}

The electrostatic potential about assemblies of surfactant graphene mixture, $\Psi(z)$, along the $z$-axis simulation box, correlated with local charge density, $\rho(z)$, through the Poisson equation

$$
\frac{d^{2} \Psi(z)}{d z^{2}}=-\frac{\rho(z)}{\varepsilon \varepsilon_{0}}
$$

Here $\varepsilon=78.5$ is the relative dielectric permittivity of water at room temperature. To calculate $\Psi(z)$, we first divided the simulation box into a number of thin slices and obtained the mass density of surfactant ions $\varepsilon_{0}=8.85 \times 10^{-12} \mathrm{C} / \mathrm{m} . \mathrm{V}$ is the vacuum dielectric permittivity

\section{References}

Ahmadin Hashem, et al. (2019). Computational Methods For Graphite Delamination Using Anionic Surfactants To Produce Graphene. Rev. Invest. Univ. Quindío 2019. 31: p. 41-53. Appel A., Thomann R., and Mülhaupt R. (2012). Polymer, 2012. 22: p. 493. 
Bari, R., et al. (2014). Direct exfoliation of graphene in ionic liquids with aromatic groups. Colloids and Surfaces A: Physicochemical and Engineering Aspects, 2014. 463: p. 6369.

Behling, E.; Marín, J.C. (2012). Biodegradación de fenol en un sistema de tratamiento combinado UASB + RBC, Revista de la Universidad del Zulia, 3 (5), 61-81

Bernal, J.D. (1924). The structure of graphite. Proceedings of the Royal Society of London. Series A, Containing Papers of a Mathematical and Physical Character, 1924. 106(740): p. 749-773.

Bjork Jonas, et al. (2010). Adsorption of Aromatic and Anti-Aromatic Systems on Graphene through $\pi-\pi$ Stacking |J. Phys. Chem. Lett, 2010. 1: p. 3407-3412.

Blanch, A.J., C.E. Lenehan, and J.S. Quinton (2010). Optimizing Surfactant Concentrations for Dispersion of Single-Walled Carbon Nanotubes in Aqueous Solution. J. Phys. Chem. B 2010. 114: p. 9805-9811

Boardman, J., et al. (2008). The Cambridge Ancient History;. Vol. 3. 2008, U.K: Cambridge University Press: Cambridge,

Bourlinos, A., V. Georgakilas, and R.Z. (2006). Theodore Liquid-phase exfoliation of graphite towards solubilized graphenes. Small, 2006. 5(16): p. 1841-1845.

Bunch, J.S., et al. (2007). Electromechanical resonators from graphene sheets. Science, 2007. 315(5811): p. 490-493.

Ciesielski, A., and P. Samorì (2014). Graphene via sonication assisted liquid-phase exfoliation. Chem. Soc. Rev, 2014. 43: p. 381-938

Coleman, J.N. (2012). Liquid exfoliation of defect-free graphene. Accounts of chemical research, 2012. 46(1): p. 14-22.

Du, X., et al. (2008). Approaching ballistic transport in suspended graphene. Nature nanotechnology, 2008. 3(8): p. 491.

Eredia, M., et al. (2017). Morphology and electronic properties of electrochemically exfoliated graphene. The journal of physical chemistry letters, 2017. 8(14): p. 3347-3355.

Haar, S.b., et al. (2016). Liquid-phase exfoliation of graphite into single-and few-layer graphene with $\alpha$-functionalized alkanes. The journal of physical chemistry letters, 2016. 7(14): p. 27142721.

Heard, K.W., et al. (2019). Initial Studies Directed toward the Rational Design of Aqueous Graphene Dispersants. ACS Omega, 2019. 4(1): p. 1969-1981.

Javadian, S. and M. Khosravian (2018). Revealing Factors Governing Self-Assembly Morphology of Fatty Acid on Graphene Synthesized by Surfactant-Assisted LPE: A Joint MD, SAPT (DFT), and Experimental Study. The Journal of Physical Chemistry C, 2018. 122(37): p. $21387-21400$.

Li, D., et al. (2008). Processable aqueous dispersions of graphene nanosheets. Nature nanotechnology, 2008. 3(2): p. 101. 
Lin, S., et al. (2011). Radical cation Diels-Alder cycloadditions by visible light photocatalysis. Journal of the American Chemical Society, 2011. 133(48): p. 19350-19353.

Liu, N., et al. (2008). One-step ionic-liquid-assisted electrochemical synthesis of ionic-liquidfunctionalized graphene sheets directly from graphite. Advanced Functional Materials, 2008. 18(10): p. 1518-1525.

Lomeda, J.R., et al. (2008). Diazonium functionalization of surfactant-wrapped chemically converted graphene sheets. Journal of the American Chemical Society, 2008. 130(48): p. 16201-16206.

Monajjemi, M. (2017). Liquid-phase exfoliation (LPE) of graphite towards graphene: An ab initio study. Journal of Molecular Liquids, 2017. 230: p. 461-472.

Morozov, S., et al. (2008). Giant intrinsic carrier mobilities in graphene and its bilayer. Physical review letters, 2008. 100(1): p. 016602.

Nacken, T., et al. (2015). Delamination of graphite in a high pressure homogenizer. Rsc Advances, 2015. 5(71): p. 57328-57338.

Nayaran, R., et al. (2017). Perylene tetracarboxylate surfactant assisted liquid phase exfoliation of graphite into graphene nanosheets with facile re-dispersibility in aqueous/organic polar solvents. Carbon, 2017. 119: p. 555-568.

Novoselov, K.S., et al. (2004). Electric field effect in atomically thin carbon films. science, 2004. 306(5696): p. 666-669.

Porsargol, A.S., et al. (2014). Interactions and structure of ionic liquids on graphene and carbon nanotubes surfaces. Rsc Advances, 2014. 4(35): p. 18017-18024.

Ravula Sudhir, et al. (2015). Ionic liquid-assisted exfoliation and dispersion: stripping graphene and its two-dimensional layered inorganic counterparts of their inhibitions Nanoscale 2015: p. 115.

Sabziparvar, A., et al. (2019). Barriers to achieving highly dispersed graphene oxide in cementitious composites: An experimental and computational study. Construction and Building Materials, 2019. 199: p. 269-278.

Stankovich, S., et al. (2006). Graphene-based composite materials. nature. 442(7100): p. 282.

Stankovich, S., et al. (2007). Synthesis of graphene-based nanosheets via chemical reduction of exfoliated graphite oxide. carbon, 2007. 45(7): p. 1558-1565.

Sun, H. and X. Yang (2014). Molecular simulation of self-assembly structure and interfacial interaction for SDBS adsorption on graphene. Colloids and Surfaces A: Physicochemical and Engineering Aspects, 2014. 462: p. 82-89.

Vaisman, L., H.D. Wagner, and G. Marom (2006). The role of surfactants in dispersion of carbon nanotubes. Advances in colloid and interface science, 2006. 128: p. 37-46.

Wang, X., et al. (2010). Direct exfoliation of natural graphite into micrometre size few layers graphene sheets using ionic liquids. Chemical Communications, 2010. 46(25): p. 4487-4489.

Wu, B. and X. Yang (2013). Molecular simulation of electrolyte-induced interfacial interaction 
between SDS/graphene assemblies. The Journal of Physical Chemistry C, 2013. 117(44): p. 23216-23223.

$\mathrm{Wu}, \mathrm{D}$. and X. Yang (2012). Coarse-grained molecular simulation of self-assembly for nonionic surfactants on graphene nanostructures. The Journal of Physical Chemistry B, 2012. 116(39): p. 12048-12056.

Xia, Z.Y., et al. (2013). Graphene: The Exfoliation of Graphene in Liquids by Electrochemical, Chemical, and Sonication-Assisted Techniques: A Nanoscale Study (Adv. Funct. Mater. 37/2013). Advanced Functional Materials, 2013. 23(37): p. 4756-4756.

$\mathrm{Xu}, \mathrm{Z}$., X. Yang, and Z. Yang (2010). A molecular simulation probing of structure and interaction for supramolecular sodium dodecyl sulfate/single-wall carbon nanotube assemblies. Nano letters, 2010. 10(3): p. 985-991.

Yang, S., et al. (2015). Organic radical-assisted electrochemical exfoliation for the scalable production of high-quality graphene. Journal of the American Chemical Society, 2015. 137(43): p. 13927-13932.

Zhang, K., et al. (2018). Direct exfoliation of graphite into graphene in aqueous solution using a novel surfactant obtained from used engine oil. Journal of materials science, 2018. 53(4): p. 2484-2496.

Zheng, W., et al. (2011). Effect of cation symmetry on the morphology and physicochemical properties of imidazolium ionic liquids. The Journal of Physical Chemistry B, 2011. 115(20): p. 6572-6584.

Zu, S.-Z. and B.-H. Han (2009). Aqueous dispersion of graphene sheets stabilized by pluronic copolymers: formation of supramolecular hydrogel. The Journal of Physical Chemistry C, 2009. 113(31): p. 1365l-13657. 